\title{
OCULOPALATAL MYOCLONUS: EYE MOVEMENT STUDIES, MRI FINDINGS AND THE DIFFICULTY OF TREATMENT
}

\author{
S. J. TALKS and J. S. ELSTON \\ Oxford
}

\begin{abstract}
SUMMARY
Two cases of oculopalatal myoclonus with bilateral horizontal gaze palsies are presented. The abnormal vertical eye movements developed several months after brain stem haemorrhage. Eye movement measurements showed rhythmical vertical eye movements at similar rates $(2.3 \mathrm{~Hz}$ and $2.4 \mathrm{~Hz})$, unaffected by attempts to fixate, converge or gaze in any direction. T2-weighted MRI scans showed bilateral enlargement of the inferior olivary nuclei in both cases, which confirms the expected pathology previously demonstrated on autopsy. Both patients had severe oscillopsia and an attempt was made to improve this by bilateral disinsertion of the vertical rectus muscles. The pendular eye movements continued but were greatly reduced, in one case enough to relieve the oscillopsia. However, after 6 months retrobulbar botulinum toxin was required to continue to provide relief from the oscillopsia. Other treatment options, including pharmacological agents, are discussed.
\end{abstract}

Palatal myoclonus was first described in $1886 .{ }^{1}$ It consists of continuous rhythmical movements of the soft palate, sometimes in association with synchronous movements of the face, upper arm or diaphragm. Occasionally there are also pendular vertical eye movements and the condition is then called oculopalatal myoclonus. $^{2.3}$ It causes debilitating oscillopsia. Two cases are presented in which we have assessed the eye movements, performed MRI and attempted to provide relief of the symptoms. The treatment options are reviewed.

\section{CASE REPORTS}

Case 1

A 54-year-old man, a former heavy smoker, presented with a 3 hour history of slurred speech and

Correspondence to: Mr S. J. Talks, Ophthalmology Department, The Radcliffe Infirmary, Woodstock Road, Oxford OX2 6HE, UK. incoordination. He was unable to stand due to ataxia and had increased tone and clonus in his legs. Reflexes were brisk in both upper and lower limbs with upgoing plantar reflexes. He had bilateral horizontal gaze palsies with no movement on vestibulo-ocular stimulation. He was unable to converge and had a right lower motor neurone VII nerve palsy. A CT scan showed a brain stem haemorrhage and an old temporal lobe infarct.

Two months later he developed vertical nystagmus with diplopia which was controlled by a 3 dioptre base-down prism in the left eye. He could see $6 / 12$. At 7 months he developed continuous large-amplitude vertical eye movements in both eyes, with oscillopsia. Vision deteriorated to 6/36. Two months later he developed palatal movements synchronous with the ocular movements. The gaze palsies did not improve and he remained confined to a wheelchair due to ataxia.

One year after his initial presentation he underwent bilateral inferior and superior rectus disinsertions. Tenon's capsule was oversewn to prevent reattachment to the globe. This greatly reduced the amplitude of vertical movement but did not eliminate it. His oscillopsia was controlled but he became aware of horizontal diplopia for near due to his inability to converge. This was helped by patching one eye. After 6 months, however, he was again troubled by some oscillopsia. This was relieved by the use of retrobulbar botulinum toxin injection $(10$ units Dysport), which has been repeated after 6 months. He has now been followed up for a year and we would expect to give repeat injections at 4-6 monthly intervals.

\section{Case 2}

A 74-year-old hypertensive woman was found unconscious. She responded only to painful stimuli. Two days later she regained consciousness but had a right hemiplegia and absent gag reflex. She was fed 

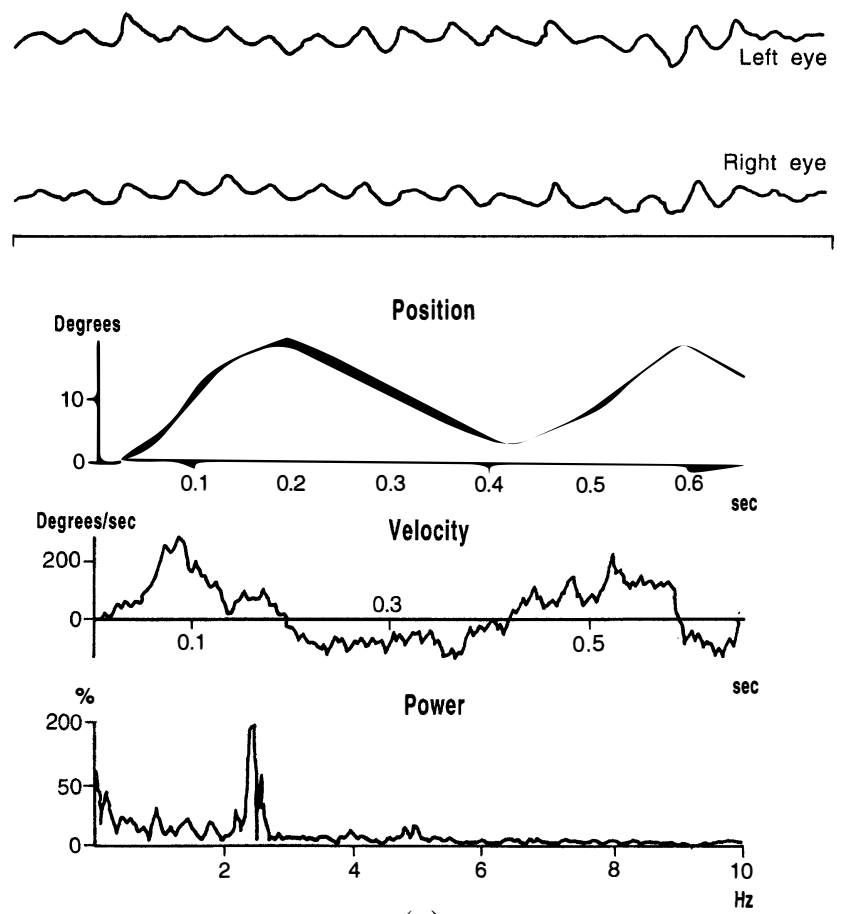

(a)
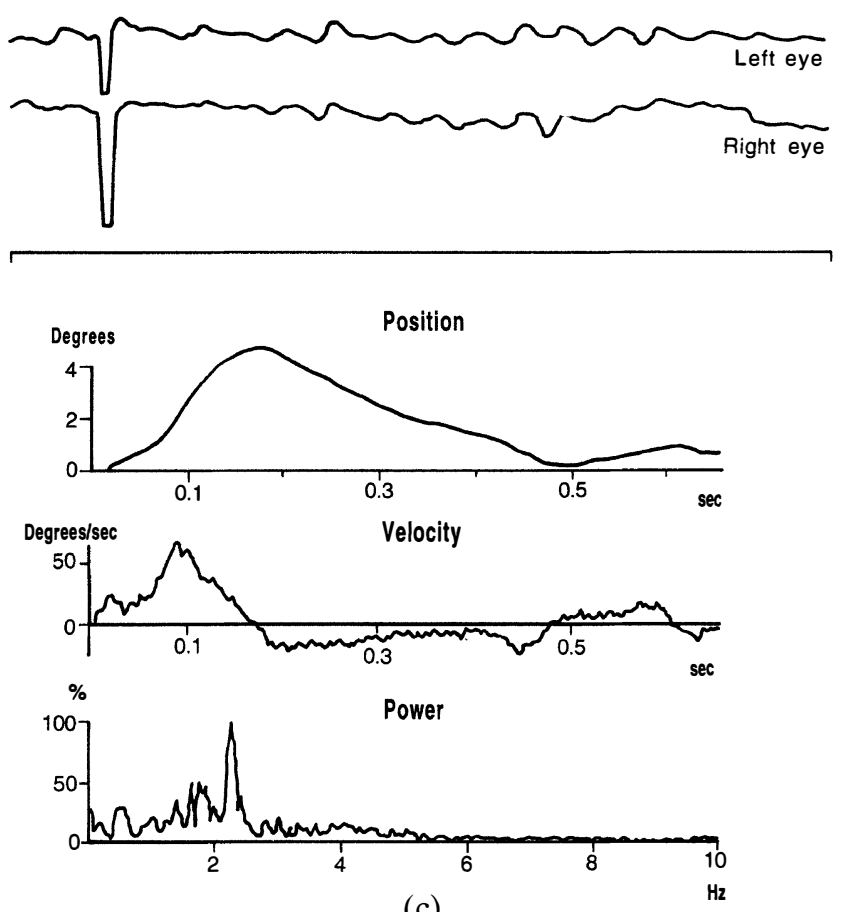

(c)

by a nasogastric tube for the first month but gradually managed liquid food, although choking has remained a problem. Her mental state remained good. After 1 year she was referred to the ophthalmic department. She was able to sit in a wheelchair. She had severe oscillopsia, causing her to spend most of the day with her eyes closed. Her visual acuity was 6/36. She had been treated with timoptol $0.5 \%$ b.d. for open angle glaucoma, but had maintained good visual acuity at $6 / 9$ and almost full fields. On examination she had bilateral large-
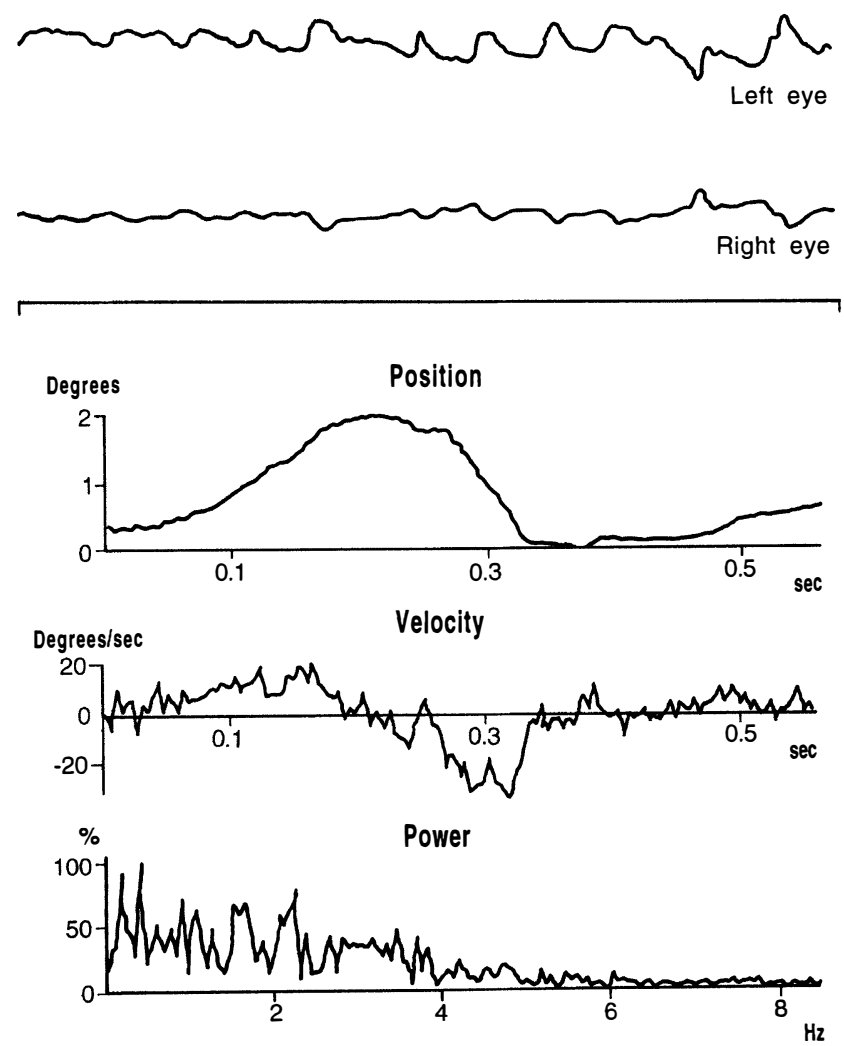

(b)

Fig. 1. Eye movement studies. (a) Case 1 before surgery. (b) Case 1 after surgery. (c) Case 2 after surgery. Top trace shows free-running eye movements. Lower traces show an analysis of one oscillation of the eye. Fourier analysis of the power spectrum shown on the bottom trace reveals a frequency of eye movement of $2.4 \mathrm{~Hz}$ in case 1 and $2.3 \mathrm{~Hz}$ in case 2.

amplitude rhythmical vertical eye movements, intermittent blepharospasm, a left gaze palsy and a partial right gaze palsy. There were synchronous palatal as well as head and upper body movements. Baclofen had caused a transient improvement in vision. She was also taking sodium valproate $400 \mathrm{mg}$ b.d. which had reduced the tremor a little but had had no effect on the eye movements. After 18 months the inferior and superior recti were disinserted in both eyes, as in case 1 . This reduced the amount of vertical movement but did not eliminate it. The oscillopsia was 


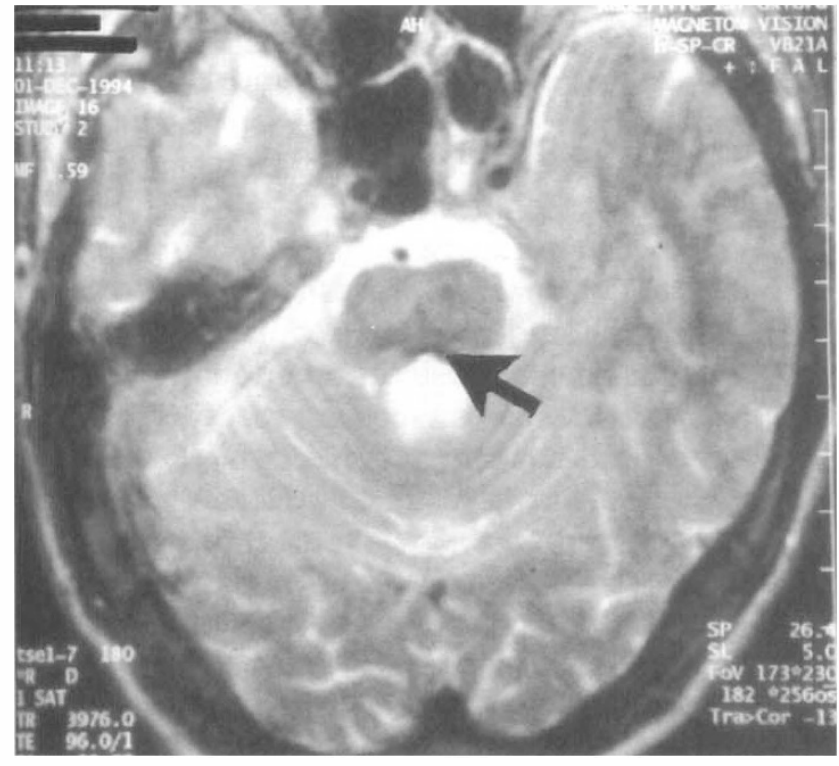

(a)

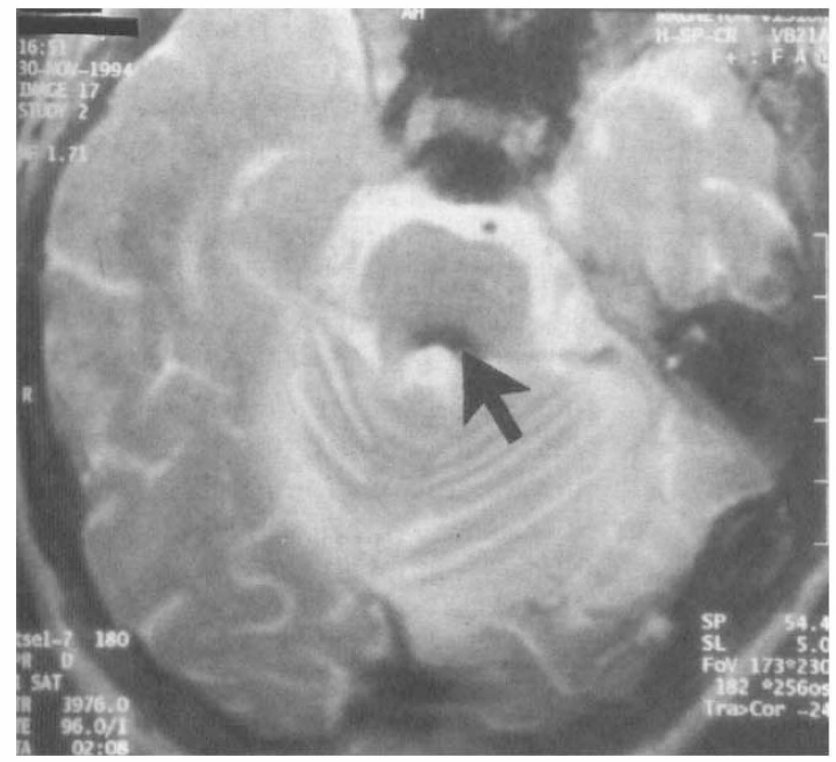

(c)

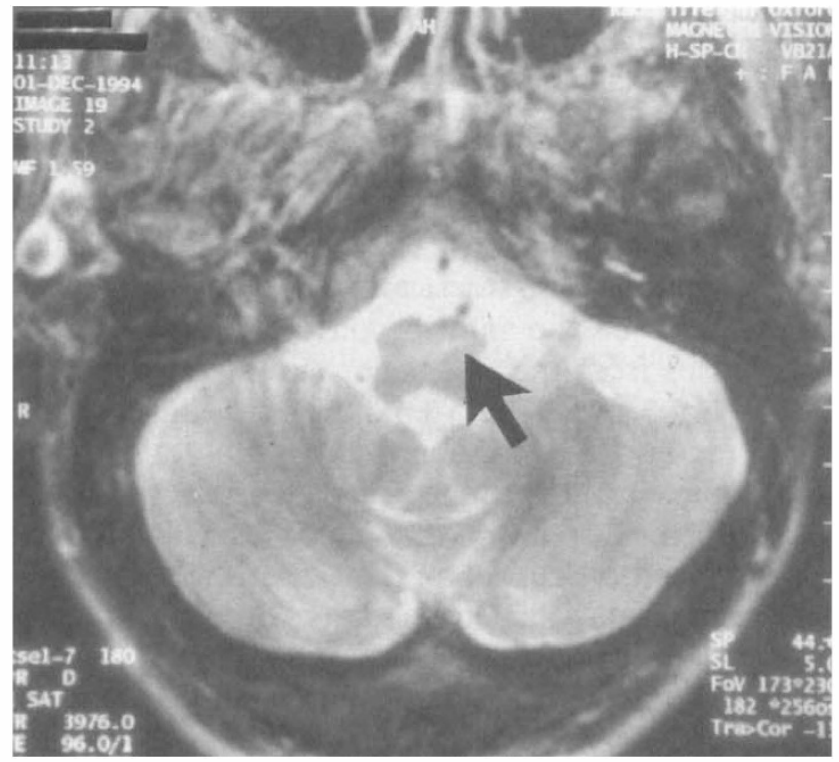

(b)

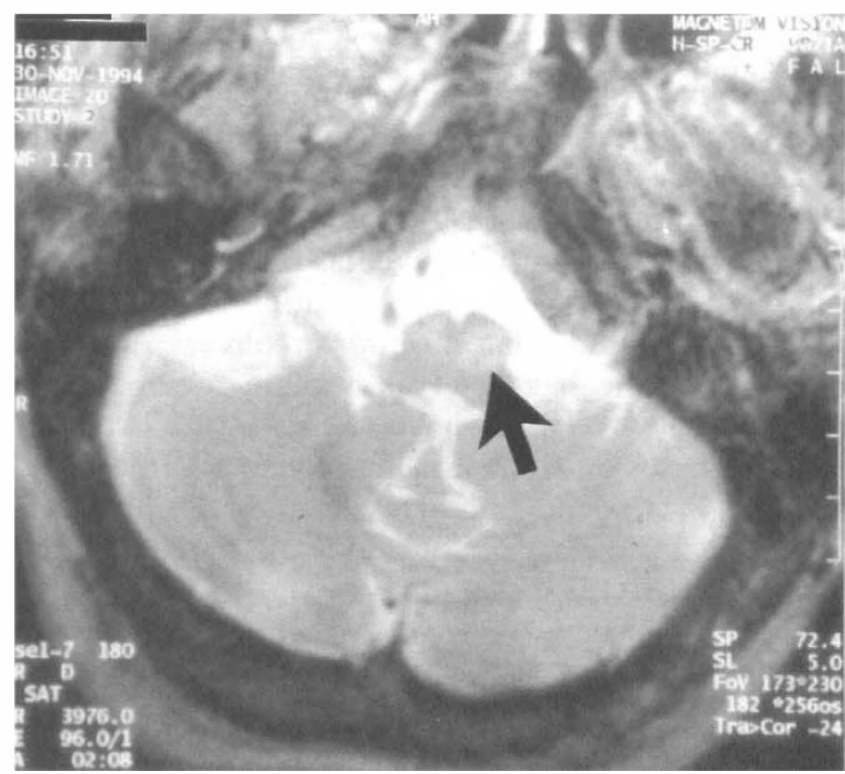

(d)

Fig. 2. MRI scans of brain stem in case $1(a, b)$ and case $2(c, d)$. (a, c) Blood in IV ventricle. (b, d) Increased signal intensity reveals inferior olivary enlargement.

initially reduced but at 3 months after surgery her symptoms had largely returned, although less so in the right eye. Her left eye was therefore patched. She declined treatment with retrobulbar botulinum toxin, mainly due to the difficulties of attending hospital regularly.

\section{Eye Movement Studies}

The eye movements of the two cases were measured with infrared reflectometry. This was carried out before and after surgery in case 1 and only after surgery in case 2 . The average frequency of the pendular movements, calculated by Fourier analysis of the traces, was $2.4 \mathrm{~Hz}$ in case 1 and $2.3 \mathrm{~Hz}$ in case
2. In case 1 the amplitude of the eye movements was reduced by surgery but the rhythm of the movements continued unabated. The pendular movements were unaffected by attempts to fixate, converge or gaze in any direction (Fig. 1).

\section{$M R I$ and CT Scan Findings}

On T2-weighted MRI both cases showed bilateral enlargement of the inferior olivary nuclei, with increased signal intensity and blood in the fourth ventricle (case 1, Fig. 2a, b; case 2, Fig. 2c, d).

The MRI scan was taken 10 months after the initial presentation in case 1 and after 14 months in case 2 . CT scans taken at the time of the acute event showed 
brain stem haemorrhages, but it was not possible to resolve the exact site of damage.

\section{DISCUSSION}

Oculopalatal myoclonus follows a lesion in the dento-rubro-olivary tract and is associated with enlargement of the inferior olivary nuclei. ${ }^{4.5}$ This tract passes from the cerebellar dentate nucleus via the superior cerebellar penduncle to the contralateral red nucleus and then to the ipsilateral inferior olivary nucleus through the central tegmental tract. ${ }^{6,7}$ Damage to the central tegmental tract produces enlargement of the ipsilateral inferior olive. Damage to the dentate nucleus results in contralateral enlargement. In some cases bilateral inferior olivary enlargement occurs. Correspondingly oculopalatal myoclonus may be bilateral or unilateral. The bilateral or midline form tends to show pendular movements whereas the lateral form may have more rotatory movements. ${ }^{8}$ Both our cases were midline forms.

As we have shown this enlargement of the inferior olivary nuclei can be seen with an MRI scan. In both our cases bilateral inferior olivary enlargement was found. In unilateral cases of oculopalatal myoclonus the contralateral inferior olive has been shown to be enlarged on MRI. ${ }^{9}$ Only 3 previous MRI reports have documented bilateral inferior olivary enlargement in clinical cases of midline oculopalatal myoclonus. $^{10-12}$ There have been a total of 17 reported cases of MRI showing olivary enlargement, but only 4 with oculopalatal myoclonus. ${ }^{13-16}$. In some cases olivary enlargement has not been demonstrated on MRI. ${ }^{11,17}$ This may relate to the quality of the scan or sensitivity of the method, as pathologically almost all patients with oculopalatal myoclonus have enlarged inferior olives. Typical MRI findings are increased signal intensity on proton- or T2-weighted images and enlargement of the inferior olives. ${ }^{9,11}$

There is a latency of 2-49 months for olivary enlargement to develop. ${ }^{18}$ This is similar to the time delay in onset of the rhythmical movements. The inferior olivary enlargement is thought to occur secondarily to transneuronal degeneration. ${ }^{4}$ The pathological changes consist of enlargement and vacuolation of neurones, neuronal loss, gliosis and astrocytic hypertrophy. ${ }^{19-21}$ In the majority of cases oculopalatal myoclonus follows a brain stem haemorrhage, as in our two cases. All the cases in which MRI has been performed showed evidence of previous brain stem haemorrhage. Oculopalatal myoclonus, can, however, occur with certain neoplasms, degenerative diseases, encephalitis, after trauma and with multiple sclerosis. ${ }^{22}$

The eye movements in oculopalatal myoclonus are usually pendular vertical movements, although rota- tory and oblique movements have been described. ${ }^{3,8}$ The frequencies of the pendular movements were very similar in the two cases $(2.3$ and $2.4 \mathrm{~Hz})$ and similar to the frequencies found by Gresty et al. ${ }^{3}$ who recorded a mode of between 2.6 and $3 \mathrm{~Hz}$ with a mean of $3.6 \mathrm{~Hz}$ in 16 cases of pendular nystagmus, although not all these cases had oculopalatal myoclonus. Itoh and $\mathrm{Sakata}^{23}$ reported frequencies of 2-3 Hz. In some of these cases various movements modified the nystagmus, such as saccades or near gaze, but we did not find any modifying factor.

Why the rhythm is at $2.3-2.4 \mathrm{~Hz}$ and what the source of this rhythm is is uncertain, especially because of the wide range of body movements involved, from the palate to the diaphragm. The role of the inferior olive is uncertain as the pathology is of degeneration. In view of the diversity of structures involved it may be that the rhythm relates to a property of neuronal function rather than the particular neuronal circuit involved. ${ }^{3}$ Inferior olivary neuronal cell membranes have been found to generate cycles of excitation and inhibition. ${ }^{24}$ Another theory is that the pendular eye movements are due to an instability in the vestibulo-ocular reflex adaptation mechanism, as a result of a dysfunction in the inferior olive leading to inappropriate oscillatory discharges by the floccular Purkinje cells. ${ }^{8}$ In both our cases the vestibulo-ocular reflex was absent. Increased glucose metabolism has been shown in the region of the inferior olive on positron emission tomography in palatal myoclonus, but not in the one patient with oculopalatal myoclonus. ${ }^{25}$ An alternative argument is that the inferior olive is not the generator of palatal myoclonus but that the nucleus ambiguus and adjacent dorsolateral reticular formation may be, as they are involved in rhythmic activity such as respiration. ${ }^{17}$

Patients with oculopalatal myoclonus are often severely debilitated with poor mobility. They may well be mentally alert and find oscillopsia a particularly serious addition to their handicaps. Treatment is difficult. Numerous pharmacological agents have been tried with varying success. Good results have been documented in case reports with sodium valproate, ${ }^{26}$ phenytoin, ${ }^{27}$ carbamazepine, ${ }^{28}$ clonazepam, ${ }^{29}$ trihexyphenidyl, ${ }^{30}$ 5-hydroxytryptophan plus carbidopa, ${ }^{31}$ hyoscine $^{3}$ and baclofen. ${ }^{32}$ However, in other case reports these agents have been documented not to help..$^{3,6,32,33}$ Treatment has also been tried without much success with prochlorperazine, tetrabenazine and diazepam., ${ }^{3,6,34}$ Sedation can be a problem. One of our patients had been treated with baclofen and sodium valproate without success.

Optical dampening of oscillopsia has been tried using high minus-power contact lenses in conjunction with high plus-power spectacles, ${ }^{35}$ but this is not 
always satisfactory. Botulinum toxin can be of benefit, either given directly into the muscles or retrobulbar. However, it needs to be given every 3-4 months and ptosis can be a problem. ${ }^{36}$ Retrobulbar botulinum toxin can also cause the loss of the vestibular ocular reflex, which may be a problem, especially in patients who can walk.

Our patients both had poor mobility and found travelling to the hospital difficult. They therefore decided to opt for surgery as an attempt at a more permanent solution. We did not feel pre-operative botulinum toxin injections would help clarify the likely success of surgery. Surgery for nystagmus is usually of benefit where there is a null point and is carried out to correct a compensatory head posture. ${ }^{37}$ Surgery to try to decrease the nystagmus itself and to control oscillopsia has not frequently been performed. Retroequatorial recessions of the horizontal recti for congenital nystagmus have been found to have some success. ${ }^{38}$ Detaching an extraocular muscle and fixing it to periosteum has been tried. ${ }^{39}$ Spalton et al. ${ }^{32}$ carried out $10 \mathrm{~mm}$ recessions on the inferior and superior rectus of one eye of a patient with ocular myoclonus without success. We disinserted the inferior and superior recti of both eyes in both patients to try to produce a maximum decrease in vertical movements. In case 2 this only dampened the oscillations mildly, but in case 1 it did provide temporary relief of oscillopsia. The much reduced oscillopsia was then controlled by botulinum toxin injections. Surgery of this nature could lead to vertical diplopia, but with surgery to both eyes this would not be expected to be a problem. Much more of a problem is adequate control of the vertical oscillations.

In conclusion, MRI in oculopalatal myoclonus can help confirm the diagnosis by showing inferior olivary enlargement. Surgery may help reduce oscillopsia but additional botulinum toxin injections may be required.

We would like to acknowledge the help of M. R. Baker, DPhil, ARCS, Research Scientist, and P. Anslow, FRCR, Consultant Radiologist, in preparing this paper.

Key words: Oculopalatal myoclonus, MRI, Nystagmus, Rectus muscle.

\section{REFERENCES}

1. Spencer HR. Pharyngeal and laryngeal 'nystagmus'. Lancet 1886;2:702.

2. Guillian G. The syndrome of synchronous and rhythmic palato-pharyngo-laryngo-oculo-diagphragmatic myoclonus. Proc R Soc Med 1938;31:1031-8.

3. Gresty MA, Ell JJ, Findley LJ. Acquired pendular nystagmus: its characteristics, localising value and pathophysiology. J Neurol Neurosurg Psychiatry 1974;37:570-7.

4. Gautier JC, Blackwood W. Enlargement of the inferior olivary nucleus in association with lesions of the central tegmental tract or dentate nucleus. Brain 1961;84: 341-61.

5. Koeppen AH, Barron KD, Dentinger MP. Olivary hypertrophy: histochemical demonstration of hydrolytic enzymes. Neurology 1980;30:471-80.

6. Guillain G, Mollaret P, Bertrand I. Sur la lésion responsable du syndrome myoclonique du tronc cérébral. Etude anatomique d'un cas demonstratif sans lésions focales. Rev Neurol 1933;3:666-74.

7. Lapresle J. Rhythmic palatal myoclonus and the dentato-olivary pathway. J Neurol 1979;220:223-30.

8. Nakada T, Kwee IL. Oculopalatal myoclonus. Brain 1986;109:431-41.

9. Chang YY, Tsia TC, Shih PY, Liu LS. Unilateral symptomatic palatal myoclonus: MRI evidence of contralateral inferior olivary lesion. Kaohsiung J Med Sci 1993;9:371-6.

10. Sperling MR, Herrmann C Jr. Syndrome of palatal myoclonus and progressive ataxia: two cases with magnetic resonance imaging. Neurology 1985; 35:1212-4.

11. Yokota T, Hirashima F, Furukawa T, Tsukagoshi $H$, Yoshikawa H. MRI findings of inferior olives in palatal myoclonus. J Neurol 1989;236:115-6.

12. Massry GG, Chung SM. Magnetic resonance imaging findings in oculopalatal myoclonus. Am J Ophthalmol 1994;117:811-2.

13. Uchino A, Hasuo $K$, Uchida $K$, Matsumoto $S$, Tsukamoto Y, Ohno M, Masuda K. Olivary degeneration after cerebellar or brain stem haemorrhage; MRI. Neuroradiology 1993;35:335-8.

14. Zarranz JJ, Fontan A, Forcadas I. MR imaging of presumed olivary hypertrophy in palatal myoclonus. AJNR 1990;11:1164.

15. Hirono N, Kameyama M, Kobayashi Y, Udaka F, Mezaki T, Abe K, Nishitani N. MR demonstration of a unilateral olivary hypertrophy caused by pontine tegmental hematoma. Neuroradiology 1990;32:340-2.

16. Revel MP, Mann M, Brugieres P, Poirier J, Gaston A. MR appearance of hypertrophic olivary degeneration after contralateral cerebellar hemorrhage. AJNR 1991;12:71-2.

17. Keane JR. Acute vertical ocular myoclonus. Neurology 1986;36:86-9.

18. Matsuo F, Ajax ET. Palatal myoclonus and denervation supersensitivity in the central nervous system. Ann Neurol 1979;5:72-8.

19. Goto N, Kaneko M. Olivary enlargement: chronological and morphometric analyses. Acta Neuropathol 1981;54:275-82.

20. Kurachi M, Nakamura I, Katsukawa K, Kobayashi K, Sano Y, Isaki K, Yamaguchi N. Olivary hypertrophy in a case with palatal myoclonus: light and electron microscopic study. Folia Psychiatr Neurol Jpn 1985; 39:543-50.

21. Pierot K, Cervera-Pierot P, Delattre JY, Duyckaerts C, Chiras J, Brunet P. Palatal myoclonus and inferior olivary lesions: MRI pathologic correlation. J Comput Assist Tomogr 1992;16:160-3.

22. Deuschl G, Mischke G, Schenck E, Schulte-Monting J, Lucking CH. Symptomatic and essential rhythmic palatal myoclonus. Brain 1990;113:1645-72.

23. Itoh Y, Sakata E. Acquired pendular oscillations after brain stem hemorrhage. Acta Otolaryngol 1989; (Suppl)468:205-8.

24. Llinas RR, Yarom Y. Electrophysiological properties of mammalian inferior olivary cells in vitro. In: Courville J, de Montigny C, Lemarre Y, editors. The 
olivary nucleus: anatomy and physiology. New York: Raven Press, 1980:379-88.

25. Dubinsky RM, Hallett M, Di Chiro G, Fulham M, Schwankhaus J. Increased glucose metabolism in the medulla of patients with palatal myoclonus. Neurology 1991;41:557-62.

26. Lefkowitz D, Harpold G. Treatment of ocular myoclonus with valproic acid. Ann Neurol 1985;17:103-4.

27. Ferro LM, Castro-Caldas A. Palatal myoclonus and carbamazepine. Ann Neurol 1981;10:402.

28. Sakai T, Shiraishi S, Murakami S. Palatal myoclonus responding to carbamazepine. Ann Neurol 1981; 9:199-200.

29. Gledhill RF, Wiles CM. Clonazepam and branchial myoclonus. Ann Neurol 1977;1:306-7.

30. Jabbari B, Gunderson CH. Palatal myoclonus responding to trihexyphenidyl. Ann Neurol 1983;14:95.

31. Magnussen I, Dupont E, Prange-Hansen A, et al. Palatal myoclonus treated with 5-hydroxytryptophan and a decarboxylase inhibitor. Acta Neurol Scand 1977;55:251-3.

32. Spalton DJ, Sanders MD, Gresty M, Rosen ES. Ocular myoclonus and oscillopsia: a problem of treatment. Trans Ophthalmol Soc UK 1980;100:507-8.

33. Carlow TJ. Medical treatment of nystagmus and ocular motor disorders. Int Ophthalmol Clin 1986;26:251-64.

34. Jankovic J, Pardo R. Segmental myoclonus: clinical and pharmacologic study. Arch Neurol 1986;43:1025-31.

35. Leigh RJ, Rushton DN, Thurston SE, et al. Effects of retinal image stabilization in acquired nystagmus due to neurologic disease. Neurology 1988;38:122-7.

36. Ruben ST, Lee JP, O'Neil, Dunlop I, Elston JS. The use of botulinum toxin for treatment of acquired nystagmus and oscillopsia. Ophthalmology 1994; 101:783-87.

37. Lee JP. Surgical management of nystagmus. Eye 1988;2:44-7.

38. von Noorden GK, Sprunger DT. Large rectus muscle recessions for the treatment of congenital nystagmus. Arch Ophthalmol 1991;109:221-4.

39. Colburn JE. Fixation of the external rectus muscle in nystagmus and paralysis. Am J Ophthalmol 1906; 23:85-8. 